\title{
MICHEL FOUCAULT E A ARQUEALOGIA/GENEALOGIA DO PODER: DA SOCIEDADE DISCIPLINAR A BIOPOLÍTICA
}

\author{
André Leonardo Copetti Santos ${ }^{1}$ \\ Maiquel Ângelo Dezordi Wermuth ${ }^{2}$
}

\begin{abstract}
Resumo
Busca-se no presente artigo empreender - a partir das principais obras do autor - uma análise de dois temas centrais no pensamento de Michel Foucault, quais sejam: as perspectivas arqueológica e genealógica de sua abordagem e a correspondente construção dos conceitos de sociedade disciplinar e de biopolítica. O problema que orienta o texto pode ser assim sintetizado: em que medida a arqueologia/genealogia do poder que marca a investigação filosófica foucaultiana assume relevância para a compreensão do fenômeno jurídico na contemporaneidade, particularmente no que se refere ao movimento de transição/sobreposição que o autor observa entre o modelo disciplinar de organização da sociedade para o modelo biopolítico? A delimitação do presente trabalho a esses dois aspectos da reflexão foucaultiana deve-se à compreensão de que reside neles uma alta potencialidade para a construção de múltiplos olhares críticos sobre o fenômeno jurídico, especialmente em relação a distintos aspectos do poder que lhe subjazem. Como método de pesquisa, foi empregado o compreensivo racionalista, não no sentido de aplicação de pré-juízos racionalistas à investigação, mas sim na perspectiva de evidenciar-se racionalmente conceitos centrais foucaultianos e suas possíveis conexões de sentido com o campo jurídico.
\end{abstract}

Palavras-Chave: Arqueologia; genealogia; sociedade disciplinar; biopolítica; fenômeno jurídico.

\section{CONSIDERAÇÕES INTRODUTÓRIAS}

Michel Foucault (1926-1984) é um dos filósofos mais lidos e comentados do século XX. Sua vasta obra assume posição central na discussão dos mais variados temas, já que o autor contribuiu no sentido de criar ou redefinir conceitos que são chave para o pensamento contemporâneo. Graças a Foucault, diversas disciplinas dentre as quais se pode destacar a história, a filosofia, a crítica literária, a sociologia e, no caso deste texto, o direito precisaram repensar seus próprios métodos e noções-chave que se pensava já consolidadas.

\footnotetext{
${ }^{1}$ Pós-Doutorando pela Universidade do Vale do Rio dos Sinos (UNISINOS) e pela Universidade de Santiago do Chile (USACH). Professor do Mestrado em Direitos Humanos da UNIJUÍ e do Programa de Pós-Graduação em Direito da URI, Santo Ângelo, RS. Coordenador Executivo do PPGD/URISAN. Editor da Revista Científica Direitos Culturais. Membro fundador da Casa Warat Buenos Aires e da Editora Casa Warat.E-mail: andre.co.petti@hotmail.com

${ }^{2}$ Doutor em Direito Público pela UNISINOS. Professor do Mestrado em Direitos Humanos da UNIJUÍ. Professor dos Cursos de Graduação em Direito da UNIJUÍ e UNISINOS. E-mail: madwermuth@gmail.com
} 
Nesse sentido, a problemática orientadora da pesquisa que deu origem ao presente texto pode ser sintetizada na seguinte objeção: em que medida a arqueologia/genealogia do poder que marca a investigação filosófica foucaultiana assume relevância para a compreensão do fenômeno jurídico na contemporaneidade, particularmente no que se refere ao movimento de transição/sobreposição que o autor observa entre o modelo disciplinar de organização da sociedade para o modelo biopolítico?

Uma vez formulado o problema de pesquisa, parte-se da hipótese de que há, sem dúvida alguma, em várias obras foucaultianas como, por exemplo, "Vigiar e Punir", "A Verdade e as Formas Jurídicas", "Microfísica do Poder", "História da Loucura" e "História da Sexualidade" uma relação direta com o campo jurídico. Sem prejuízo das incontáveis possibilidades de conexão que podem ser estabelecidas com o direito a partir dos escritos de Foucault, a delimitação do presente trabalho a esses dois aspectos da reflexão foucaultiana - sociedade disciplinar e biopolítica - deve-se à alta potencialidade neles residente para a construção de múltiplos olhares críticos sobre o fenômeno jurídico, especialmente em relação a distintos aspectos do poder que lhe subjazem.

Objetiva-se, portanto, com o presente artigo, analisar dois temas centrais no pensamento de Foucault: as perspectivas arqueológica e genealógica de sua abordagem e a correspondente construção dos conceitos de sociedade disciplinar e de biopolítica e algumas possíveis relações com o campo discursivo e analítico do direito, mais especificamente no que se refere à temática da guerra, que assume, na contemporaneidade, o aspecto de um regime de biopoder.

Para a consecução do objetivo, o texto encontra-se estruturado em três tópicos distintos: em um primeiro momento, busca-se compreender o modus operandi por meio do qual Michel Foucault empreende sua investigação histórico-filosófica, buscando-se demonstrar a importância da investigação arqueológica e genealógica para o campo jurídico; em um segundo momento, busca-se compreender o conceito de sociedade disciplinar cunhado por Foucault, em especial no que se refere à produção de pequenas individualidades funcionais e adaptadas mediante investimentos microfísicos, capilares, que tem por função maior "adestrar" o indivíduo para retirar e se apropriar dele ainda mais e melhor; por fim, a análise debruça-se sobre o conceito de biopolítica, enquanto modelo de exercício de poder que se dá não mais sobre os corpos individuais, mas sobre a população como um todo, viabilizando que a potência da vida humana seja "aproveitada" pelo Estado e pelas instituições como elemento de poder, ou seja, aquele momento a partir do qual o "cuidado" em relação à vida humana passa a integrar os cálculos do poder, de modo a torná-la cada vez mais produtiva, o que deságua na discussão da morte em massa do outro em nome da melhoria da raça. Nesse ponto, procura-se analisar a biopolítica foucaultiana sob o viés da imposição de um modelo de biopoder assentado na ideia de guerra. 


\section{A RELEVÂNCIA DA INVESTIGAÇÃO ARQUEOLÓGICA E GENEALÓGICA DE MICHEL FOUCAULT PARA O CAMPO JURÍDICO}

O trabalho de Foucault é marcado por um polifacetamento que torna qualquer tentativa de categorização a seu respeito uma tarefa bastante difícil. Em uma conhecida entrevista a Paul Rabinow ${ }^{3}$ ele declarou que não era nem marxista, nem freudiano ou pós-estruturalista, ainda que seu trabalho partilhe algumas das revoluções teóricas iniciadas por esses três movimentos. Sem pretensão de categorização ou enquadramento, é possível dizer que, mesmo diante de uma pluralidade temática e de influências, Foucault conseguiu armar um eixo metodológico que deu uma considerável unidade ao seu trabalho. Essa amálgama aparece, por exemplo, na sua notável reação contra a rigidez formal do estruturalismo, especialmente em relação à insistência dessa escola de pensamento de que tudo seja classificado impecavelmente em termos de seu papel restrito no sistema. Nesse aspecto, Foucault tomou como base e aprofundou o trabalho de Gramsci sobre o problema da hegemonia, abarcando o fator hegemônico do poder na criação e manutenção dos sistemas sociais. Para ele, a criação de tais sistemas implicou a marginalização e exclusão de certos grupos sociais vulneráveis em nome da "ordem". O destino de tais grupos se tornou a questão central das suas investigações históricas: a agenda oculta que ele estava determinado a trazer à tona. Assim, por exemplo, na obra História da Loucura (1961), Foucault descreve como os doentes mentais foram deslocados para asilos que anteriormente abrigavam leprosos, sendo este o grande confinamento a partir do século XVII; ou o nascimento das prisões modernas em Vigiar e Punir (1975), ou da medicina da modernidade em $O$ nascimento da clínica (1963), ou, por fim, como a homossexualidade foi gradualmente banida pelo cristianismo em A História da Sexualidade (1976-1984), tornando-se a heterossexualidade a norma e todos os demais comportamentos sexuais anormais. Em todos esses casos o que deve ser destacado é que Foucault mostra o surgimento de formas "científicas" de controle social pelas autoridades: a vida dos indivíduos, especialmente partes vulneráveis da população, sendo rigorosamente regulamentadas, disciplinadas.

Foucault, com isso, tem como foco central a investigação do "inconsciente" do poder, e ao se lançar nessa direção, busca percorrer um caminho totalmente crítico, logrando sucesso nessa sua empreitada, uma vez que não só provê seus leitores e estudiosos de instrumentos para questionar o sentido de teorias e práticas estabelecidas, mas também mostra "as coisas como são" a partir de uma perspectiva de "como deveriam ser", apontando e analisando obstáculos a serem superados para que as potencialidades melhores presentes no existente possam se realizar. Nesse sentido é inevitável a constatação da atualidade do pensamento foucaultiano que confere à sua obra uma vitalidade que está longe de se esgotar. Ao filosofar investigando a história, Foucault deixou como legado um trabalho que não busca tão somente o conhecimento erudito das sociedades passadas, mas, antes de

${ }^{3}$ Entrevista disponível em: <http://www.foucault.info/foucault/interview.html >. Acesso em: 02 mar. 2015. vol.09, nº. 01, Rio de Janeiro, 2016.pp. 405-424 
qualquer coisa, uma melhor compreensão/reflexão da atualidade, pela confrontação com aquilo que já não mais somos. Por outro lado, a obra foucaultiana também sugere - a partir do seu perfil histórico-filosófico possibilidades de transformação da sociedade que vem.

Como um investigador da história, ele empenha-se em entender a "microfísica" do poder examinando os modos através dos quais o poder é construído e manipulado discursivamente. A questão constante em Foucault acerca de "quem se beneficia" das manipulações de poder através da linguagem é classicamente marxista, enquanto seu entendimento dos efeitos psicológicos do poder, tais como a repressão, pertencem muito à sua base freudiana.

De outra mão, Foucault deu uma forte singularidade às suas investigações através da sua perspectiva arqueológica e genealógica. Forçado a descrever ele mesmo, Foucault provavelmente diria que ele era tanto um arqueologista histórico quanto um genealogista. Em um de seus mais famosos trabalhos, "A Arqueologia do Saber", Foucault destaca que seu objeto de estudo é o "arquivo", isto é, a existência acumulada do discurso. A arqueologia, como ele a entende, não é nem relacionada com a geologia (análise do subsolo), nem à genealogia (como descrição dos começos e sequências), mas é a análise do discurso em sua modalidade de arquivo. Apenas para facilitar o entendimento: "arquivo", em Foucault, é a lei do que pode ser dito, o sistema que rege o aparecimento dos enunciados como acontecimentos singulares; é o que, na própria raiz do enunciadoacontecimento e no corpo em que se dá, define, desde o início, o sistema de sua enunciabilidade; é o sistema de seu funcionamento (FOUCAULT, 1997, p.148-150).

A ideia foucaultiana de uma arqueologia do pensamento está muito proximamente ligada à ideia literária modernista de que linguagem é uma fonte de pensamento por si só, não meramente um instrumento de expressão de ideias de quem as usa. Para Foucault, em qualquer dado período em um dado domínio, há substanciais constrangimentos sobre como estão as pessoas aptas a pensar, ademais das constrições gramaticais e lógicas propriamente ligadas à estrutura formal da língua. Em outras palavras, todos os modos de pensamento envolvem regras implícitas (talvez nem mesmo formuladas ou formuláveis por aqueles que as seguem) que materialmente restringem a gama de pensamento. Nessa perspectiva, para Foucault se nós pudermos descobrir essas regras, estaremos aptos para ver como um constrangimento aparentemente arbitrário de fato faz total sentido na estrutura de funcionamento definida por essas regras.

Foucault entende que esse nível de análise, que está fora do controle dos indivíduos que de fato fazem o pensamento em um dado período, é a chave para o entendimento dos constrangimentos e restrições nos quais as pessoas pensam. Assim, a "histórias das idéias" - onde isso significa o que está conscientemente em andamento na mente dos cientistas, filósofos e outros - é menos importante que as estruturas subjacentes que formam o contexto para seus pensamentos. O arqueólogo foucaultiano estará mais interessado, diferentemente de uma 
postura hermenêutica, em apreender não o significado dos discursos de Descartes, Hume ou Darwin, ou, trazendo para o campo jurídico, o que quiseram dizer os legisladores quando positivaram uma determinada lei, mas, num caminho distinto, quais foram as condições que tornaram possíveis o acontecimento do pensamento desses filósofos ou de determinada lei. Desse modo, a história de Foucault não é hermenêutica - ou é não hermenêutica -, isto é, ela não tenta interpretar o que ouvimos ou lemos para descobrir seus sentidos mais profundos. Ela manuseia os textos tratando-os não como documentos, mas, à maneira de um arqueologista, como monumentos. Mais do que buscar o que Descartes queria expressar em suas "Meditações", o arqueólogo usa o que Descartes - e muitos outros escritores, famosos ou não, do mesmo período - escreveu como evidência para uma estrutura geral do sistema no qual eles pensaram e escreveram. Para sintetizar impecavelmente a concepção metodológica arqueológica em Foucault, é de destacar-se que o interesse, para invocar a analogia arqueológica uma vez mais, não está no objeto (texto) estudado, mas na configuração mais geral do lugar de onde ele foi escavado.

Há, nesse sentido, o que se costuma denominar como a "marginalização do sujeito" em Foucault. Isto não quer dizer que ele nega a realidade ou mesmo a importância ética suprema da consciência individual. Apenas ele pensa que os indivíduos operam em um ambiente conceitual que determina e limita-os nos modos nos quais eles não podem estar cientes. A arqueologia de Foucault objetiva, assim, uma história sem os sujeitos individuais, mas ao contrário do que é geralmente dito, isto não significa a total exclusão do sujeito da história. Foucault está falando, apesar disto, sobre a nossa história. O que é preciso destacar é que a arqueologia enfatiza que o estágio no qual a história é protagonizada pelos indivíduos - bem como muito do script - está estabelecido independentemente dos pensamentos e ações das pessoas. Assim, a arqueologia introduz fatores externos à consciência dos seres humanos que podem desmentir a continuidade e a direção que os indivíduos leem e interpretam em suas vidas.

Foucault, como arqueologista, descobre os códigos culturais calcificados que determinam práticas culturais - se essas práticas têm a ver com a forma como a cultura classifica e trata a loucura, a criminalidade, a sexualidade ou outras questões. A prática cultural é a regra que governa como a cultura trata aquilo que desafia as crenças e opiniões consolidadas. É essa perspectiva que permite a Foucault apresentar uma detalhada explicação das súbitas mudanças no pensamento e no discurso que determinam como a cultura trata comportamentos não conformes. Uma das contribuições de Foucault para o entendimento do tratamento do desvio está em seu foco sobre o papel da "exclusão" nesse empreendimento. Sem exclusão não há código: regras de comportamento são definidas pelo que elas excluem assim como pelo que elas permitem. Escrevendo no "Discurso sobre Linguagem", Foucault observa que a "produção do discurso", modos de falar sobre e de entender o fenômeno cultural, "é ao mesmo tempo controlada, selecionada, organizada e redistribuída de acordo com certo número de 
procedimentos, cujo papel é evitar seus poderes e seus perigos, enfrentar eventos fortuitos e escapar de suas mentalidades incríveis e difíceis" (ADAMS; SEARLE, 1986, 149).

O discurso para Foucault é um modo de falar a respeito de questões ou temas culturais; o discurso é também caracterizado por sua função de censura: tanto em pensamentos habilitados quanto não habilitados nos quais cuidadosamente guarda - através da linguagem que permite e proíbe - as fronteiras cuidadosamente construídas do aceitável. Disciplinas - categorias de estudo - tais como a ciência, matemática, psicologia, etc, são mecanismos de discurso ideal porque, como Foucault explica, eles "constituem um sistema de controle na produção de discurso tomando a forma de uma permanente reativação de regras" (ADAMS; SEARLE, 1986, 155). Assim, na ciência, por exemplo, a hipótese deve ser provável no paradigma estruturado pela análise científica. Para uma hipótese científica ser provada verdadeira, assim, ela deve cumprir a condição de reprodutibilidade: se as conclusões dos experimentos não são reprodutíveis em várias e diferentes condições, então elas não são verificáveis, e em razão disso, não são "verdades". Enquanto tais protocolos podem parecer muito razoáveis a um primeiro olhar, a arqueologia foucaultiana permite avançar na sua análise para entender os possíveis efeitos deletérios do controle disciplinar.

Por outro lado, Foucault não possui um projeto de explicar ideias por forças econômicas ou sociais externas, à maneira do marxismo ou outras formas de materialismo histórico, apesar de haver influências marxistas em sua constituição como pensador. Seu projeto está mais voltado a oferecer uma descrição do pensamento humano, sem assumir um status privilegiado para o conteúdo consciente do pensamento - pensamento sem um papel privilegiado para o pensador, paralelo à escrita sem um papel privilegiado para o escritor, nos moldes assumidos pela vanguarda modernista.

O que Foucault realiza com sua proposta de análise dos constrangimentos e restrições do pensamento é um esforço, característico de muitos dos filósofos desde Kant, para determinar as "condições de possibilidade" de nossos conceitos e experiências. Kant, por exemplo, chamou estas condições de transcendentais. Enquanto para Kant tais condições eram universalmente aplicáveis, necessariamente constrangedoras sobre todas as possíveis experiências, para Foucault, em sentido diverso, elas são contingentes numa particular situação histórica e variam sobre tempos e domínios de conhecimento.

Em contraste com a arqueologia, mas também como uma complementação, a genealogia de Foucault traça as origens e modulações de uma prática cultural desde os primeiros dias até a encarnação nos dias atuais. Um bom exemplo disso é o exame empreendido por Foucault em "Vigiar e Punir" acerca de como a invenção do panopticon, por Jeremy Bentham, revolucionou o modo pelo qual o controle governamental é exercido sobre todos os cidadãos, seja no sistema penal, seja na vida cotidiana, a partir da ideia de sociedade disciplinar, tema abordado no tópico a seguir. 


\section{O CONCEITO DE SOCIEDADE DISCIPLINAR NA OBRA DE MICHEL FOUCAULT}

Foucault, na abertura de "Vigiar e Punir", apresenta a descrição espetacularmente brutal da execução de Robert Damien, por um regicídio contra Luis XV (ou um parricídio, pois o rei era o pai de todos os cidadãos) perpetrado em 5 de janeiro de 1757. Acusado e condenado, o réu foi executado menos de dois meses após o fato, sendo esquartejado em praça pública. Em ato contínuo aos comentários do texto que se refere à execução de Damien, Foucault (1987, p. 10), abruptamente muda seu foco para outro documento, datado de 1837, no qual de declaram as regras para um centro de detenção de jovens infratores em Paris: "o dia do prisioneiro começará às seis da manhã no inverno e cinco no verão. Eles trabalharão nove horas diárias ao longo do ano. Duas horas por dia serão dedicadas à instrução. $O$ trabalho e o dia terminarão às nove horas no inverno e às oito no verão". Após citar esta e mais onze regras similares, Foucault (1987, p. 11) finalmente aventura um comentário: "apresentamos exemplo de suplício e de utilização do tempo."

Dois exemplares modos de punição: o primeiro ocorrido ao final do Iluminismo, mais tipicamente a punição adotada para os criminosos na Europa até a metade do século XVIII; o segundo representou a nova fórmula, um modo mais gentil de punição, uma aproximação mais humana para punir. Essa segunda forma, na explicação de Foucault, levou ao mais desenvolvido sistema moderno que ele chama "disciplina”

A pergunta que Foucault busca responder acerca da nova ideia de punição - grosseiramente, o aprisionamento mais que a tortura - diz respeito ao fato de ela representar um progressivo desenvolvimento? Foucault (1987, p. 102) tem suas dúvidas, sugerindo que o ponto era "não punir menos, mas punir melhor". Avançando na sua análise acerca desses dois modos de punição, ele começa destacando os contrastes entre as abordagens moderna e pré-moderna de punição:

1. A punição não é mais uma apresentação pública, uma demonstração espetacular para todos da soberania irresistível, mas mais uma discreta, quase uma vergonhosa aplicação de constrangimentos necessários para preservar a ordem pública;

2. O que é punido não é mais o crime, mas o criminoso; a preocupação da lei não é mais o que o criminoso fez, mas o que o levou a praticar o crime;

3. Os que determinam a precisa natureza e a duração da punição não são mais os juízes, que impõem punições de acordo com a lei, mas especialistas (psiquiatras, assistentes sociais, comitês de avaliação) que decidem como implementar sentenças judiciais indeterminadas;

4. O propósito declarado publicamente da punição não é mais a retribuição, mas a reforma e reabilitação do criminoso.

Foucault não nega que a cessação dos esquartejamentos de criminosos é um avanço. Mas a conversão obscura do modo gentil de punição é uma propensão para um controle total. Em um plano, isso é assinalado por _vol.09, nº. 01, Rio de Janeiro, 2016.pp. 405-424 
uma mudança da brutal, mas não focada, punição física para uma menos dolorosa, mas mais invasiva forma de controle. A punição pré-moderna assalta violentamente o corpo do criminoso, sendo satisfeita com a retribuição através da dor; já o modelo moderno de punição demanda uma transformação interna, uma conversão do coração para um novo modo de vida. Na visão de Foucault esse controle moderno da alma significa, mais além, uma mais sutil e penetrante forma de controle do corpo, de controlar corporalmente o comportamento.

A mais notável tese de "Vigiar e Punir" é que as técnicas disciplinares introduzidas para os criminosos se tornam o modelo para outros lugares modernos de controle, tais como escolas, fábricas, hospitais etc., assim como a prisão impregna a sociedade moderna. Nós vivemos, diz Foucault (1987, p. 323), em um "arquipélago carcerário".

Pode-se dizer que Foucault constrói, assim, por meio de uma história das técnicas utilizadas para o exercício do poder disciplinar sobre o corpo, uma genealogia da alma moderna. Esta "alma", também denominada de consciência, psique, subjetividade, jamais é uma realidade preexistente sobre a qual atuam os mecanismos punitivos; antes, somente é constituída como alma porque há um investimento político sobre o corpo, através da utilização de uma tecnologia do poder sobre esse corpo (FOUCAULT, 1987, p. 34). Na fábrica, na escola, no hospital, no convento, no regimento militar ou na prisão trata-se sempre da constituição de uma anatomia política pela distribuição espacial dos indivíduos e o controle de suas atividades; ou pela combinação dos corpos e das forças, de modo a deles extrair a máxima utilidade. Ao ser o corpo parte de um espaço, núcleo de um comportamento, soma de forças que se aglutinam, torna-se possível adestrá-lo e torná-lo útil. A anatomia política do corpo fabrica pequenas individualidades funcionais e adaptadas mediante investimentos microfísicos, capilares. Daí a importância do detalhe do gesto e da minúcia do olhar (CANDIOTTO, 2012).

Foucault (1987, p. 195) refere que o poder disciplinar é um poder que:

Em vez de se apropriar e de retirar, tem como função maior 'adestrar'; ou sem dúvida adestrar para retirar e se apropriar ainda mais e melhor. Ele não amarra as forças para reduzilas; procura ligá-las para multiplicá-las e utilizá-las num todo. [...] 'Adestra' as multidões confusas, móveis, inúteis de corpos e forças para uma multiplicidade de elementos individuais - pequenas células separadas, autonomias orgânicas, identidades e continuidades genéticas, segmentos combinatórios. A disciplina 'fabrica' indivíduos; ela é a técnica específica de um poder que toma os indivíduos ao mesmo tempo como objetos e como instrumentos de seu exercício. [...] O sucesso do poder disciplinar se deve sem dúvida ao uso de instrumentos simples: o olhar hierárquico, a sanção normalizadora e sua combinação num procedimento que the é específico, o exame.

Uma das intuições importantes apresentadas por Foucault em Vigiar e puniré a descrição dos mecanismos da microfísica do poder, uma espécie de combinação entre vigilância hierárquica e sanção normalizadora, que conflui no exame disciplinar. A disciplina se vale da vigilância como um de seus mecanismos mais eficazes. Foucault mostra que efeitos de poder, tais como o autocontrole dos gestos e atitudes, são produzidos não somente pela violência e pela força, mas sobremaneira pela sensação de estar sendo vigiado. 
Engana-se quem pensa ser a sociedade disciplinar aquela na qual todos se vigiam, como se houvesse um acréscimo de guardas e disciplinadores. Pelo contrário, nas instituições de vigilância precisou-se cada vez menos desses personagens. O poder disciplinar é econômico. Ele se vale de espaços arquiteturais organizados de modo a incrementar e facilitar a sensação de vigilância múltipla, detalhada e minuciosa de cada indivíduo que compõe seus interiores. Assim é que hospitais, fábricas e escolas funcionam como microscópios do comportamento humano, ao possibilitarem a um único olhar tudo ver, permanentemente. Mas esse único olhar não necessariamente é de uma pessoa, já que o importante deixa de ser que alguém, de fato, esteja vendo. O olho anônimo do poder e sua estruturação arquitetural é que impelem o indivíduo a se autodisciplinar. Com as palavras do próprio Foucault (1987, p. 192):

Em resumo, pode-se dizer que a disciplina produz, a partir dos corpos que controla, quatro tipos de individualidade, ou antes uma individualidade dotada de quatro características: é celular (pelo jogo da repartição espacial), é orgânica (pela codificação das atividades), é genética (pela acumulação do tempo), é combinatória (pela composição das forças). E, para tanto, utiliza quatro grandes técnicas: constrói quadros; prescreve manobras; impóe exercícios; enfim, para realizar a combinação das forças, organiza "táticas".

A partir dessa noção de disciplina Foucault modula sua reflexão, movendo-se para uma outra ideia central de seu pensamento: a concepção de biopolítica. $\mathrm{O}$ autor estabelece um interessante paralelo entre a disciplina e a biopolítica, ao salientar que desde o final do século XVIII é possível identificar não mais apenas uma, mas duas tecnologias de poder que são introduzidas com certa defasagem cronológica e que são, na maioria das vezes, sobrepostas. Uma técnica é a disciplinar, centrada no corpo, produzindo efeitos individualizantes por meio da manipulação do corpo como foco de forças que é preciso tornar úteis e dóceis ao mesmo tempo. Por outro lado, o autor identifica uma tecnologia que é centrada não no corpo individual, mas na vida enquanto fenômeno. Trata-se de uma tecnologia que agrupa os efeitos de massas próprios de uma população e que procura controlar a série de eventos fortuitos que podem ocorrer numa massa viva com o escopo de controlar (e, eventualmente, modificar) a probabilidade desses eventos e/ou compensar seus efeitos. Trata-se, em ambos os casos, de tecnologias do corpo, mas, no primeiro caso, trata-se de uma tecnologia em que o corpo é individualizado como organismo dotado de capacidades (disciplina) e, no segundo, de uma tecnologia em que os corpos são recolocados nos processos biológicos de conjunto (biopolítica). É dessa segunda tecnologia que se ocupa o tópico que segue.

\section{A TRANSIÇÃO DO PODER DISCIPLINAR PARA A BIOPOLÍTICA EM MICHEL FOUCAULT}

O conceito de biopolítica assume posição central nos escritos foucaultianos da década de setenta do século passado e, na contemporaneidade, assume posição central para o diagnóstico e para a compreensão das 
crises e mutações políticas e jurídicas que caracterizam o novo milênio. Esse período de tempo que medeia entre a invenção do conceito por Foucault e sua "apropriação" contemporânea para a explicação de alguns fenômenos por diversos autores contemporâneos - com destaque a Giorgio Agamben, Roberto Esposito, Antonio Negri e Michael Hardt - pode ser atribuído ao fato de que a profundidade do tema fez com que o conceito precisasse de praticamente duas décadas de intenso debate para ser "definitivamente compreendido, absorvido e apropriado por outros autores", como observa Duarte (2010, p. 205).

Por biopolítica, pode-se compreender uma cada vez maior implicação da vida natural do homem nos mecanismos e cálculos do poder. O termo é utilizado por Foucault para designar o modo por meio do qual o poder se encaminha para a transformação, entre o apagar das luzes do século XVIII e o alvorecer do século XIX, rumo a uma forma de governo que não tem por destinatários os indivíduos singularmente considerados - por meio de uma série de procedimentos disciplinares, como analisado no tópico precedente -, mas também o conjunto dos seres vivos que compõem a população. Nesse sentido, "a biopolítica - por meio dos biopoderes locais - se ocupará [...] da gestão da saúde, da higiene, da alimentação, da sexualidade, da natalidade etc., na medida em que tais gestões se tornaram apostas políticas" (REVEL, 2011, p. 24).

Na concepção de Foucault (2010, p. 201-202), a biopolítica, ou seja, essa "assunção da vida pelo poder" ou "estatização do biológico" foi "um dos fenômenos fundamentais do século XIX" e representa um câmbio importante em relação à teoria clássica da soberania: se na teoria clássica da soberania o soberano, ao deter o poder em relação à vida e à morte do súdito, poderia fazê-lo morrer ou deixá-lo viver, a biopolítica é o fenômeno que vai completar esse velho direito de soberania "com outro direito novo, que não vai apagar o primeiro, mas vai penetrá-lo, perpassá-lo, modificá-lo, e que vai ser um direito, ou melhor, um poder exatamente inverso: poder de 'fazer' viver e de 'deixar' morrer." Na mesma linha de raciocínio, "pode-se dizer que o velho direito de causar a morte ou deixarviver foi substituído por um poder de causara vida ou devolverà morte." (FOUCAULT, 2012, p. $150)$.

Foucault (2012) procura, então, demonstrar o importante deslocamento que ocorreu na passagem do século XVIII para o século XIX na forma de exercício do poder soberano: ele deixa de se afirmar enquanto um poder de "matar a vida" e passa a fazê-lo enquanto um poder que "gerencia a vida", um poder que tem por objetivo o saneamento do corpo da população de modo a depurá-lo de todas as infecções internas. O poder, agora, passa a ser exercido sobre a vida, fixando-se ao longo de todo o seu desenrolar. A morte é o momento que escapa a esse poder, é o seu limite, ou seja, o momento mais "privado" da existência de uma pessoa.

Segundo Foucault (2003, p. 80), o capitalismo que se desenvolvia no final do século XVIII e no início do século XIX foi o responsável pela socialização de um primeiro objeto que foi o corpo enquanto força de produção, de trabalho. Nessa ótica, a formação do capitalismo ocasiona justamente a entrada da vida humana na história. No 
sistema capitalista de produção, instrumentalizar o saber sobre a vida é imprescindível, uma vez que viabiliza tanto o controle quanto a inserção das pessoas nos processos de produção. Há, com isso, um ajuste dos fenômenos naturais (nascimento, reprodução, morte) aos processos econômicos. O objetivo é controlar as consequências dos fenômenos naturais de modo que elas signifiquem ganhos econômicos. O acoplamento entre a biopolítica e o capitalismo, assim, é viabilizado/evidenciado: por meio de controles diversos sobre a vida (demografia, higiene pública, projetos de urbanismo, etc) transforma-se os indivíduos em população, ou seja, produz-se um grande - e produtivo - "corpo mecânico".

Isso evidencia que "o controle da sociedade sobre os indivíduos não se opera simplesmente pela consciência ou pela ideologia, mas começa no corpo, com o corpo", afinal, "o corpo é uma realidade bio-política." Portanto, "é o fato do poder encarregar-se da vida, mais do que a ameaça da morte, que lhe dá acesso ao corpo." (FOUCAULT, 2012, p. 155).

O processo de inscrição da vida na política por meio da biopolítica é um dos temas sobre os quais a análise foucaultiana $(1987,2003,2012)$ dos mecanismos de poder ${ }^{4}$ vai se debruçar. A biopolítica nasce no rastro da disciplina, com a particularidade de que, enquanto esta, nos séculos XVII e XVIII, era voltada essencialmente ao corpo individual, colimando a sua adaptação ao trabalho - tecnologia disciplinar do trabalho, portanto -, aquela representa uma segunda tomada de poder, não mais sobre o corpo individual, mas sobre as massas. Passase, a partir da segunda metade do século XVIII, do homem-corpo para o homem-espécie, no momento em que à dicotomia homem-sociedade passa a ser agregada a noção de população.

Torna-se possível, diante do exposto, a afirmação de que Foucault chega aos conceitos de biopolítica e biopoder quando vislumbra um câmbio operado ao longo do século XVII e XVIII - sobretudo na virada para o século XIX - da forma como se estrutura o poder: se antes ele era a soma de micropoderes disciplinares que tinham por objetivo a administração do corpo individual, ou seja, que partiam de uma visão do corpo enquanto máquina - o que se vislumbra pela gradativa formação de instituições como a escola, o hospital, o exército e a fábrica, cujos objetivos centravam-se no adestramento dos corpos individuais e na extorsão de suas forças

\footnotetext{
${ }^{4}$ Aqui, é importante referir que "o conceito de poder para Foucault não deve ser equivalente aos conceitos de repressão, lei, soberania, instituições e aparelhos do Estado como comumente é analisado. Foucault não se refere a uma forma de sujeição realizada por leis e regras, nem a um sistema de dominação de uns sobre outros. Ao contrário, poder é entendido como multiplicidade de correlações de forças, como jogo, estratégias móveis. Ou seja: poder visto como potencialidade criadora, própria do ser humano, que se faz aparecer nas práticas e nas relações humanas. Falamos de poder enquanto relação de forças, enquanto prática, enquanto poder circulante, não estático nem centralizado em um ponto. Falamos de exercício de poder e não de aquisição do mesmo. O poder também não pertence a alguém, isto é, não provém de uma relação entre dominados e dominadores; não é uma instância dual, binária, mas sim uma instância onipresente, isto é, se produz a cada instante, em todos os pontos, em todas as relações." (BOFF, 2008, p. 190).

Sobre esse tema, Duarte (2010, p. 212) assevera que, em Foucault, "o poder é sempre plural e relacional, exercendo-se em práticas heterogêneas e sujeitas a transformações no interior de instituições sociais determinadas. O poder se dá em um conjunto de relações e práticas sociais constituídas historicamente, que atuam por meio de dispositivos estratégicos dos quais ninguém escapa, pois não há região da vida social que esteja isenta de seus mecanismos."
} 
paralelamente ao crescimento de sua utilidade e docilidade, de modo a integrá-lo a sistemas de controle eficazes -, agora o poder disciplinador e normalizador já não mais é exercido sobre os corpos individualizados, mas sim sobre o corpo-espécie, e tampouco se encontra disseminado em instituições sociais. Ele passa a se concentrar na figura do Estado e se exerce a título de política estatal que objetiva a administração da vida e do corpo da população.

Para Foucault (2010, p. 206-207), "a biopolítica lida com a população, e a população como problema político, como problema a um só tempo científico e político, como problema biológico e como problema de poder. " Logo, os fenômenos que passam a ser levados em consideração, aqui, são os coletivos, ou seja, aqueles "que só aparecem com seus efeitos econômicos e políticos, que só se tornam pertinentes no nível da massa”, o que significa dizer que "a biopolítica vai se dirigir, em suma, aos acontecimentos aleatórios que ocorrem numa população considerada em sua duração."

Por biopoder, portanto, Foucault vai designar a inclusão da vida mesma no âmbito de ação estatal por meio de políticas sanitárias, urbanísticas ou educativas. O soberano, aqui, aprende a dizer sim, passando do não proibitivo ao sim governativo. O poder passa a ser visto como condução de si mesmo e dos outros, uma intensificação e totalização da dominação que é acompanhada, paradoxalmente, por sua limitação. Na obra na qual inaugura a discussão acerca da biopolítica, Foucault (2012, p. 156) destaca: "o homem, durante milênios, permaneceu o que era para Aristóteles: um animal vivo e, além disso, capaz de existência política; o homem moderno é um animal, em cuja política, sua vida de ser vivo está em questão."

A biopolítica, ao contrário dos mecanismos disciplinares, não vai buscar a alteração do indivíduo, não se ocupa dos fenômenos individuais, dos homens isoladamente considerados. A partir de previsões, estimativas, estatísticas e medições, ela vai priorizar as intervenções nos fenômenos em nível global, com o escopo de estabelecer mecanismos reguladores que, "nessa população global com seu campo aleatório, vão poder fixar um equilíbrio, manter uma média, estabelecer uma espécie de homeostase, assegurar compensações". Quer dizer: vai se preocupar em "instalar mecanismos de previdência em torno desse aleatório que é inerente a uma população de seres vivos" de forma a "otimizar [...] um estado de vida." (FOUCAULT, 2010, p. 207).

É nesse momento, portanto, que se percebe "a potência da vida humana que é 'aproveitada’ pelo Estado e pelas instituições como elemento de poder", ou seja, passa-se a incluir a vida humana nos cálculos do poder, sendo a lógica do biopoder justamente "cuidar da vida humana a fim de que ela seja produtiva." (BOFF, 2008, p. 193). A potência da morte que outrora simbolizava o poder soberano, portanto, passa a ser recoberta pela administração dos corpos, pela gestão calculista da vida.

O foco, na biopolítica, deixa de ser o corpo individual, a consideração do indivíduo no nível do detalhe como na disciplina. Esses mecanismos disciplinares - que visavam à docilidade dos corpos, ou seja, ao disciplinamento dos corpos, e também do tempo e do espaço, de modo a adaptá-los e torná-los úteis ao sistema 
de produção vigente - são substituídos por mecanismos globais que objetivam estados globais de equilíbrio, de regularidade. Com efeito, na medida em que se "normaliza" a população, em que se "regulamenta" a população, torna-se mais fácil controlá-la e otimizar a sua produtividade.

Na perspectiva foucaultiana, torna-se importante analisar a forma como ambos os mecanismos de poder - o disciplinar e o regulamentador -, se relacionam: em que pese não estarem no mesmo nível, não há um processo de auto-exclusão, mas de articulação. A origem das "sociedades do controle" contemporâneas está justamente nas técnicas disciplinares de padronização dos corpos nas instituições ao longo dos séculos XVII e XVIII e que nos séculos XX e XXI espraia-se para a sociedade como um todo, objetivando a normalização dos indivíduos em diversas instâncias, induzindo comportamentos - como, por exemplo, determinados padrões de consumo - e fabricando subjetividades não autênticas.

O que vai permitir essa articulação entre as duas formas de exercício de poder identificadas é a norma, uma vez que ela "é o que pode tanto se aplicar a um corpo que se quer disciplinar quanto a uma população que se quer regulamentar." Logo, a sociedade de normalização não é outra coisa senão "uma espécie de sociedade disciplinar generalizada cujas instituições disciplinares teriam se alastrado e finalmente recoberto todo o espaço", ou seja, "uma sociedade em que se cruzam, conforme uma articulação ortogonal, a norma da disciplina e a norma da regulamentação. " Por meio desses mecanismos - disciplina e regulamentação - o poder, a partir do século XIX, passa a incumbir-se da vida, quer dizer, "ele conseguiu cobrir toda a superfície que se estende do orgânico ao biológico, do corpo à população, mediante o jogo duplo das tecnologias de disciplina, de uma parte, e das tecnologias de regulamentação, de outra." (FOUCAULT, 2010, p. 213).

O paradoxo que se apresenta, nesse viés, diz respeito a como conciliar o direito de matar com um exercício de poder preocupado essencialmente com a vida, seja no que concerne a aumentá-la, seja no que se refere a prolongá-la ou, ainda, multiplicar suas possibilidades à medida que desvia seus acidentes e compensa suas deficiências. A grande questão que se coloca então é como se pode exercer o poder da morte em um sistema político centrado no biopoder.

O mecanismo que vai permitir o exercício desse poder de morte em um regime de biopoder é o racismo, compreendido a partir de uma dupla perspectiva: em um primeiro momento, o racismo pode ser visto como um meio de introduzir no domínio da vida - de que o poder se incumbiu - o corte entre o que deve viver e o que deve morrer. Para Foucault (2010, p. 214),

No contínuo biológico da espécie humana, o aparecimento das raças, a distinção das raças, a hierarquia das raças, a qualificação de certas raças como boas e de outras, ao contrário, como inferiores, tudo isso vai ser uma maneira de fragmentar esse campo do biológico de que o poder se incumbiu; uma maneira de defasar, no interior da população, uns grupos em relação aos outros. [...]. Essa é a primeira função do racismo: fragmentar, fazer cesuras no interior desse contínuo biológico a que se dirige o biopoder. 
Já a segunda função do racismo será legitimar a morte do "outro" a partir de uma maneira inteiramente nova, compatível com o biopoder: a partir de então, "a morte do outro, a morte da raça ruim, da raça inferior (ou do degenerado, ou do anormal), é o que vai deixar a vida em geral mais sadia, mais sadia e mais pura." A eliminação do perigo biológico representado pelo outro é legitimada, dessa maneira, conforme estiver diretamente relacionada ao fortalecimento da própria espécie ou da raça: "a função assassina do Estado só pode ser assegurada, desde que o Estado funcione no modo do biopoder, pelo racismo" (FOUCAULT, 2010, p. 215).

O refinamento da tese foucaultiana reside justamente nesse ponto: a biopolítica enquanto forma encontrada pelo Estado para "gerir a vida da população" não pode ser ingenuamente compreendida pelo seu "caráter humanitário" de administrar, por meio de intervenções políticas, as condições de vida da população. Há um aspecto violento desse controle, denunciado pelo autor, que reside justamente na exigência contínua e crescente da morte em massa do "outro", enquanto instrumento privilegiado para a garantia de melhores meios de sobrevivência de uma determinada população: "o poder de expor uma população à morte geral é o inverso do poder de garantir a outra sua permanência em vida.” (FOUCAULT, 2012, p. 149).

Toda biopolítica é, nessa medida, também uma tanatopolítica, ou seja, "não há contradição entre o poder de gerência e incremento da vida e o poder de matar aos milhões para garantir as melhores condições vitais possíveis." (DUARTE, 2010, p. 227). Portanto, na medida em que o biológico passa a refletir-se no político, toda forma de eugenia, de cisão entre o que é considerado normal e o que é considerado anormal, passa a ser justificado. Isso porque o biopoder, em nome da proteção à vida da população, encontra legitimidade para a eliminação de todo perigo a que esta vida possa estar exposta. Segundo Esposito (2006, p. 10-11), "el bíos es artificialmente recortado, por una serie de umbrales, en zonas dotadas de diferente valor que someten una de sus partes al dominio violento y destructivo de otra."

Em um contexto tal, pelo menos potencialmente, a vida humana é convertida em um terreno de decisões que dizem respeito não somente a seus umbrais externos (como, por exemplo, o que distingue a vida animal da vegetal), mas também a partir de seus umbrais internos, o que significa dizer que "será concedido o, más bien, exigido a la política el decidir cuál es la vida biologicamente mejor y también como potenciarla a través del uso, la explotación, o si hiciera la muerte de la vida menos valiosa biologicamente." (ESPOSITO, 2006, p. 11). O ponto de decisão reside justamente em definir em que momento uma vida deixa de ser política (e economicamente) relevante e, consequentemente, pode ser eliminada do tecido societal.

Neste estado de coisas, o racismo é condição de possibilidade para que se possa exercer o direito de matar. Nas palavras de Foucault (2010, p. 52-53), o racismo de Estado é exercido pela sociedade sobre ela mesma, ou seja, "sobre seus próprios elementos, sobre os seus próprios produtos"; trata-se de um "racismo interno, o da purificação permanente, que será uma das dimensões fundamentais da normalização social.” 
Nesse ponto, é importante consignar que, por "tirar a vida" não se compreende, na perspectiva foucaultiana (2010, p. 216), unicamente o assassínio direto, mas também tudo que pode ser considerado assassínio indireto: "o fato de expor à morte, de multiplicar para alguns o risco de morte ou, pura e simplesmente, a morte política, a expulsão, a rejeição. " Com efeito, na medida em que a biopolítica se transforma em tanatopolítica, verifica-se que o ponto de decisão entre o fazer viver e o fazer morrer desloca-se para áreas cada vez maiores da vida social - a exemplo dos refugiados, dos pacientes sujeitos à eutanásia programada, das cobaias humanas, dos comatosos, dos terroristas prisioneiros em Guantánamo, dos receptores de ajuda humanitária, dos imigrantes "sem-papel” na Europa, etc.

A guerra e o genocídio assumem, nesse quadro, o papel de ferramentas largamente utilizadas pela biopolítica para a consecução de seus objetivos. Ao mencionar que nunca na história da humanidade as guerras foram tão sangrentas como a partir do século XIX, e tampouco os regimes políticos haviam, até então, praticado tamanhos holocaustos em suas próprias populações, Foucault (2012, p. 149) salienta que o câmbio ocorre justamente em virtude do surgimento do biopoder, de modo que o "formidável poder de morte [...] apresenta-se agora como o complemento de um poder que se exerce, positivamente, sobre a vida, que empreende sua gestão, sua majoração, sua multiplicação, o exercício, sobre ela, de controles precisos e regulações de conjunto."

Em razão disso, já não são mais travadas guerras em nome da defesa do soberano, mas sim em defesa de todos, em um movimento paradoxal: populações inteiras destroem-se mutuamente em nome da necessidade de viver, ou seja, os massacres tornam-se vitais. Essa justificativa - de gestão da vida e da sobrevivência dos corpos e das raças - passa a ser utilizada pelos regimes para travar guerras que causam mortes em massa. Nesse rumo, quanto mais a tecnologia das guerras se volta para a destruição exaustiva, tanto mais as decisões que deflagram e encerram as guerras são tomadas em função da questão nua e crua da sobrevivência.

Assim, considera-se que o racismo assegura, na economia do biopoder, a função de morte, a partir do princípio de que a morte dos outros representa o fortalecimento da própria pessoa na medida em que ela é membro de uma raça ou população, ou seja, configura-se enquanto elemento de uma pluralidade unitária e viva. E é justamente aqui que reside a particularidade do racismo moderno: ela habita no fato de que ele não se encontra ligado a mentalidades, ideologias ou mentiras do poder, mas à técnica ou tecnologia do poder, atrelado ao funcionamento de um Estado que é obrigado a se utilizar da raça - da sua eliminação e da sua purificação - para que possa exercitar seu poder soberano.

Foucault (2010, p. 218) serve-se do exemplo do nazismo, por ele considerado como o desenvolvimento, até o paroxismo, dos novos mecanismos de poder introduzidos a partir do século XVIII, para explicitar sua tese: "não há sociedade a um só tempo mais disciplinar e mais previdenciária do que a que foi implantada, ou em todo caso projetada, pelos nazistas". Nessa sociedade, o controle das eventualidades próprias dos processos biológicos 
(procriação, hereditariedade, doenças, acidentes) era um dos principais objetivos do regime. No entanto, essa sociedade, ao mesmo tempo que universalmente previdenciária, seguradora, regulamentadora e disciplinar, era também perpassada, em todo o seu corpo, pelo poder de matar, que não era prerrogativa apenas do Estado, mas de toda uma série de indivíduos, de modo que, "no limite, todos têm o direito de vida e de morte sobre o seu vizinho, no Estado nazista, ainda que fosse pelo comportamento de denúncia, que permite efetivamente suprimir, ou fazer suprimirem, aquele que está a seu lado."

A guerra, no regime nazista, é colocada como um objetivo político, ou seja, a política deve resultar na guerra, sendo que "a guerra deve ser a fase final e decisiva que vai coroar o conjunto." Como decorrência disso, o regime nazista não objetiva apenas a destruição das outras raças: busca-se também expor a própria raça ao perigo universal da morte. Isso significa que a defesa da vida e a produção da morte encontram-se em um patamar de indistinção. Logo, "o risco de morrer, a exposição à destruição total, é um dos princípios inseridos entre os deveres fundamentais da obediência nazista, e entre os objetivos essenciais da política. ” Busca-se o ponto no qual toda a população esteja exposta à morte, dada compreensão de que "apenas essa exposição universal de toda a população à morte poderá efetivamente constituí-la como raça superior e regenerá-la definitivamente perante as raças que tiverem sido totalmente exterminadas ou que serão definitivamente sujeitadas. " (FOUCAULT, 2010, p. 218219).

Entre a atitude terapêutica e a tanatopolítica, portanto, não há apenas contradição, mas também conexão/complementação. As mortes em massa, no regime nazista, decorreram diretamente da preocupação obsessiva com a saúde do povo alemão. Segundo Esposito (2010, p. 166-167), os médicos nazistas identificavam como "doente" o povo alemão no seu conjunto e "era precisamente a sua cura que requeria a morte de todos aqueles que pela sua simples existência lhe ameaçavam a saúde."

Esposito (2006) salienta que a biopolítica assume na contemporaneidade uma posição central, o que se evidencia, por exemplo, a partir da relevância cada vez maior dado ao elemento étnico nas relações internacionais, do impacto das biotecnologias sobre o corpo humano, da centralidade da questão sanitária como índice privilegiado de funcionamento do sistema econômico-produtivo, da prioridade da exigência de segurança em todos os programas de governo, etc.

Além disso, não só a possibilidade da destruição em massa de toda a população é responsável pela manutenção do biopoder, mas também a individualização da violência: "quando chega a se individualizar em sua forma extrema, o biopoder transforma-se em tortura." (HARDT; NEGRI, 2005, p. 41). Essa afirmação se justifica na medida em que, na contemporaneidade, assiste-se a um processo de banalização da tortura, à sua generalização enquanto técnica de controle. A tortura representa "um dos principais pontos de contato entre a ação policial e a guerra" e representa "a outra face do estado de exceção e da tendência do poder político para se furtar ao império 
da lei", uma vez que "de acordo com a lógica do estado de exceção, a tortura constitui uma técnica de poder essencial, inevitável e justificável." (HARDT; NEGRI, 2005, p. 42).

Em Guantánamo, por exemplo, métodos para obter confissões e informações por meio de tormentos físicos e psicológicos foram largamente utilizados. A privação do sono, dentre outras técnicas para desorientar os prisioneiros, ao lado de outras formas de humilhação, foram implementadas sem escrúpulos em nome da eficiência na guerra ao terror. Como refere Esposito (2006, p. 16), essas barbáries parecem conduzir à época prémoderna dos suplícios em praça pública, com um toque hipermoderno, constituído pela plateia planetária da internet: "lo virtual, más que lo opuesto a lo real, constituye, en este caso, la más concreta manifestación en el cuerpo mismo de las víctimas y en la sangre que parece salpicar la pantalla."

Hoje, a prevenção do terrorismo de massa tende a apropriar-se de suas modalidades e a reproduzi-las, o que está evidenciado por Esposito (2006, p. 17) no seguinte exemplo: "que en la reciente guerra en Afeganistán los mismos aviones hayan lanzado bombas y víveres sobre las mismas poblaciones es quizás la señal tangible de que superposición más acabada entre defensa de la vida y producción de muerte.”

Tratam-se tais técnicas, na visão de Agamben (2008, p. 155), de uma manifestação do projeto do biopoder contemporâneo de produção de uma sobrevivência modulável e virtualmente infinita, tendo em vista que "a ambição suprema do biopoder consiste em produzir em um corpo humano a separação absoluta entre o ser vivo e o ser que fala, entre a zoée o bíos, o não-homem e o homem: a sobrevivência." Isso significa que o poder soberano contemporâneo se sustenta na exclusão que se materializa na permanência (sobrevivência) do excluído.

Nesse estado de coisas, a guerra deixa de ser a ultima ratio, ou seja, o elemento final das sequências de poder para transformar-se na prima ratio, ou seja, no principal fundamento da própria política. A guerra assume a condição de única forma de coexistência global, cuja consequência, que não surpreende, é justamente uma multiplicação em excesso dos mesmos riscos que com a guerra se pretende evitar. Como resultado, tem-se uma superposição absoluta de valores opostos como paz e guerra, ataque e defesa. Em síntese: vida e morte se sobrepõem cada vez mais.

\section{CONSIDERAÇÕES FINAIS}

Uma vez apresentado sucintamente o eixo metodológico sobre o qual se estrutura o trabalho de Foucault, cabem aqui alguns apontamentos acerca de possíveis relações e aplicações da arqueologia e da genealogia foucaultianas às investigações e práticas no campo jurídico. Em primeiro lugar, a perspectiva arqueológica se apresenta como um método de trabalho científico que permite trazer à tona as estruturas e sistemas que se constituíram e se constituem como condições de possibilidade da construção dos discursos jurídicos nas suas mais diferentes facetas e funcionalidades. Assim, é possível, pela aplicação da metodologia 
arqueológica, mergulhar nas reais circunstâncias determinantes de como um discurso normativo legislativo foi elaborado de um modo e não de outro; de como juízes decidem em um sentido e não em outro.

Nesse sentido, uma abordagem arqueológica tem a função primordial de afastar "ingenuidades" positivistas-normativistas, bem como prevenir autoritarismos hermenêuticos. Para os positivistas-normativistas, tradição que ainda hoje predomina na narratividade jurídica brasileira, as restrições e constrangimentos discursivos são irrelevantes, pois basta a superficialidade do que está positivado para resolver qualquer dúvida relativa à aplicação do direito. Já em relação à sua diferença da aproximação hermenêutica, especialmente em relação a algumas novas abordagens que têm servido de substrato à elaboração de uma nova crítica ao positivismo, tais como as ideias de resposta certa dworkiana, ou a própria ideia de tradição gadameriana, a arqueologia, ao possibilitar a "escavação" das estruturas e sistemas constritores, permite a construção de um metadiscurso sobre as próprias interpretações construídas com as ferramentas da filosofia hermenêutica ou da hermenêutica filosófica. Em outras palavras, com o instrumental arqueológico é possível sempre escavar as condições de formação dos discursos e, sendo também discurso, das próprias interpretações e seus constrangimentos.

Procurou-se evidenciar isso a partir de duas categorias fundamentais do pensamento foucaultiano: a sociedade disciplinar e a biopolítica. Ao analisar os sistemas de punição pré-moderno e moderno a partir da consolidação da categoria conceitual da disciplina, Foucault transforma-se em um autor cuja leitura é indispensável para qualquer investigador ou estudioso das ciências penais, especialmente da criminologia. Essa construção de análise de Foucault, juntamente com as análises formuladas pelos investigadores da Escola de Frankfurt Rusch e Kirsheimer (na obra "Punição e Estrutura Social"), bem como com a perspectiva mais marxista lançada por Pavarini (na obra "Cárcere e Fábrica”), constitui-se, talvez, na mais importante referência crítica acerca dos sistemas penais modernos.

Da mesma forma, a noção de biopolítica cunhada na obra foucaultiana assume na contemporaneidade a feição de uma importante ferramenta conceitual para a compreensão de fenômenos como, por exemplo, a proliferação da guerra. Isso porque a biopolítica permite compreender como se dá a passagem - ou sobreposição - da sociedade disciplinar - na qual a disciplina sucedia como "anátomo-política" dos corpos e se aplicava basicamente aos indivíduos - para a sociedade do biopoder - na qual a biopolítica representa uma espécie de "medicina social" que se aplica à população com o propósito de governar sua vida. O movimento revelado pela obra foucaultiana revela, portanto, o momento a partir do qual a vida passa a fazer parte do campo do poder. Da disciplina - cujo objetivo era o adestramento dos corpos - passa-se ao biopoder - cujo objetivo é o adestramento da população, ou melhor, da vida da população, colimando retirar desse "corpo da multidão" o máximo proveito possível. 


\title{
MICHEL FOUCAULT AND ARQUEALOGIA / POWER GENEALOGY: THE DISCIPLINARY SOCIETY TO BIOPOLITICS
}

\begin{abstract}
Search in the present article take - from the main works of the author - an analysis of two central themes at the thought of Michel Foucault, namely: the archaeological and genealogical perspectives of his approach and the corresponding construction of the concepts of disciplinary society and biopolitics. The problem guiding text can be summarized thus: to what extent archeology/genealogy of power that marks the research foucault's philosophy is relevant to understanding the legal phenomenon in contemporary society, particularly with regard to the movement of transition/overlap the author notes between the disciplinary model of social organization for the bio-political model? The limits of this work to these two aspects of Foucault's reflection is due to the realization that lies in them a high potential for the construction of multiple critical perspectives on the legal phenomenon, especially in relation to different aspects of power that underlie it. As a research method, it was the rationalist understanding employee, not in the sense of application of pre-judgments rationalist research, but from the perspective of evidence rationally central concepts and their possible connections of meaning to the legal field.
\end{abstract}

Keywords: Archeology; genealogy; disciplinary society; biopolitics; legal phenomenon.

\section{REFERENCIAS}

ADAMS, Hazard; SEARLE, Leroy. Critcal theory since 1965. Tallahassee, FL: Florida State University Press, 1986.

AGAMBEN, Giorgio. O que resta de Auschwitz: o arquivo e a testemunha (Homo Sacer III). São Paulo: Boitempo, 2008.

BOFF, Adelaide Bersch. Da norma à vida: a violenta padronização do ethos. In: MARTINS, Jasson da Silva (org.). Ética, política e direito: inflexões filosóficas. São Leopoldo: Nova Harmonia, 2008. p. 189-204.

CANDIOTTO, Cesar. Disciplina e segurança em Michel Foucault: a normalização e a regulação da delinquência. In: Psicologia e Sociedade. vol.24. Belo Horizonte, 2012, p. 18-24.

DUARTE, André. Vidas em risco: crítica do presente em Heidegger, Arendt e Foucault. Rio de Janeiro: Forense Universtária, 2010.

ESPOSITO, Roberto. Biopolítica y filosofia. Buenos Aires: Grama Ediciones, 2006.

Bios: biopolítica e filosofia. Lisboa: Edições 70, 2010.

FOUCAULT, Michel. AArqueologia do Saber. 5. ed. Rio de Janeiro: Forense Universitária, 1997.

Vigiar e punir. 20. ed. Petrópolis, RJ: Vozes, 1987.

Microfísica do poder. 18. ed. São Paulo: Graal, 2003.

Em defesa da sociedade: curso no Collège de France (1975-1976). 2. ed. São Paulo: WMF Martins Fontes, 2010,

História da Sexualidade I: A Vontade de Saber. 22ª. Impressão. Rio de Janeiro: Edições Graal, 2012. 
HARDT, Michael; NEGRI, Antonio. Multidão: guerra e democracia na era do Império. São Paulo: Record, 2005.

REVEL, Judith. Dicionário Foucault. Rio de Janeiro: Forense Universitária, 2011.

Trabalho enviado em 23 de julho de 2015.

Aceito em 04 de novembro de 2015. 